\title{
Gestão ambiental e estratégia empresarial: um estudo em uma empresa de cosméticos no Brasil
}

\author{
Environmental management and business strategy: a study in a \\ cosmetic company in Brazil
}

\author{
Sandra Mara Schiavi Bánkuti ${ }^{1}$ \\ Ferenc Istvan Bánkuti²
}

\begin{abstract}
Resumo: Dentro do atual contexto competitivo, caracterizado pelo processo de globalização e por avanços tecnológicos acelerados, criam-se ambientes altamente dinâmicos, com destaque para a flexibilidade estratégica, a perspectiva global, a inteligência competitiva e a inovação. Considerando o conceito de ecoinovação, questões relativas ao meio ambiente têm tido destaque no meio concorrencial. O objetivo proposto neste trabalho é identificar e analisar ações ambientais estratégicas implantadas por empresa de capital nacional atuante no setor de cosméticos. Para tanto, foram utilizadas informações secundárias e dados primários coletados junto à empresa. Os resultados do trabalho indicaram forte alinhamento estratégico e melhorias ambientais, associados à interação entre gestão ambiental e inovações de produto, de processo, de marketing e organizacional. Percebeu-se iniciativa da alta gerência na condução dos procedimentos ambientais e a necessidade de coordenação com agentes da cadeia de suprimentos. As principais dificuldades para melhorias ambientais estão associadas à necessidade de elevados investimentos para desenvolvimento de produtos e melhorias de processo, assim como a limitações de conhecimento técnico e científico. Por fim, destaca-se a importância da interação entre agentes internos e externos para a condução de melhorias ambientais.
\end{abstract}

Palavras-chave: Gestão ambiental estratégica. Setor de cosméticos. Competitividade.

\begin{abstract}
Within the current competitive scenario, characterized by globalization and technological advances, extremely dynamic environments emerge with emphasis on flexible strategies, global perspective, competitive intelligence, and innovation. Considering the concept of eco-innovation, environmental matters have been highlighted in competitiveness. This paper aims to identify and analyze strategic environmental activities in a national enterprise from the cosmetic sector, through secondary and primary data (in loco interview). Results showed strong alignment between strategy and environmental activities, as well as interfaces with product, process marketing, and organizational innovations. Also, environmental procedures depend on initiatives of top management and supply chain coordination. The main difficulties to environmental improvements are related to high investment levels in product and process developments, as well as to limited scientific and technical knowledge. Finally, the importance of intra-firm and inter-firm interactions to conduct environmental improvements should be highlighted.
\end{abstract}

Keywords: Strategic environmental management. Cosmetic sector. Competitiveness.

\section{Introdução}

Dentro do contexto empresarial sabe-se que o meio ambiente é fonte de recursos produtivos, tais como matérias-primas, energia, solo, metais etc. Além disso, o processo produtivo tem como resultado outputs desejados, ou seja, os bens e serviços pretendidos, e indesejados, tais como resíduos e poluição. Deve-se discutir o desempenho das organizações sob diferentes enfoques, abordando-se não somente a competitividade econômica, mas também a competitividade ambiental. Segundo Farrell, Lukesch e Thirion (2000, p. 5), a competitividade ambiental pode ser definida como a
[...] capacidade dos agentes de sublinhar a importância do seu ambiente tornando-o um elemento distintivo do seu território, assegurando ao mesmo tempo a preservação e a renovação dos recursos naturais e patrimoniais.

Diferentes grupos de interesse (stakeholders), como governo, clientes e sociedade, começaram a atentar para responsabilidade ambiental e a exigir das empresas postura apropriada no que concerne ao meio ambiente (WEBER, 1999). O governo, por

\footnotetext{
${ }^{1}$ Departamento de Administração, Universidade Estadual de Maringá - UEM, Av. Colombo, 5790, CEP 87020-900, Maringá, PR, Brasil, e-mail: smsbankuti@uem.br

${ }^{2}$ Departamento de Zootecnia, Universidade Estadual de Maringá - UEM, Av. Colombo, 5790, CEP 87020-900, Maringá, PR, Brasil,e-mail: fibankuti@uem.br
}

Recebido em 6/5/2012 — Aceito em 6/12/2013

Suporte financeiro: Nenhum. 
meio da imposição de leis mais rígidas relativas às atividades empresariais e suas interações com o meio ambiente. Clientes e sociedade, ao exigirem produtos, processos e serviços mais "limpos", ou seja, com menor impacto negativo ao meio ambiente.

Assim, a gestão ambiental tem feito parte do novo cenário competitivo empresarial. O desenvolvimento de estratégias ambientalmente corretas se deve a razões principais, entre as quais podem-se destacar: (a) menor possibilidade de multas ambientais; (b) redução de custos; (c) a possibilidade de entrada em novos mercados; (d) incremento de receitas; e (e) maior valor para a marca.

Conforme destacado em relatório do United Nations Environment Programme - UNEP (2011), a indústria deve assumir um papel proativo para a Economia Verde, buscando ações e inovações para o uso eficiente de recursos e o incremento da produtividade, o que requer esforços do lado do suprimento e da demanda, ou seja, ao longo de toda a cadeia. Independentemente do setor em que a empresa atua ou da valoração que seu grupo de consumidores confere às organizações, produtos ou serviços ambientalmente mais adequados, a decisão de ser ambientalmente correta representa para a empresa uma estratégia que deve ser considerada. Entretanto, alguns setores são tidos como altamente poluentes, merecendo atenção especial do governo por meio de legislação, regulamentação e fiscalização mais rígidas, bem como de outros grupos de interesse. Exemplos são a indústria petrolífera, a de metalurgia básica, a de papel e celulose e a indústria química.

No caso do setor químico, o alcance da química sustentável, conforme Soto (2012), envolve desafios associados à periculosidade de produtos químicos, à redução do consumo energético e hídrico, à emissão de gases de efeito estufa, ao uso de matérias-primas renováveis, às atividades de pós-consumo, incluindo destinação correta dos resíduos, e ao fortalecimento dos relacionamentos ao longo da cadeia nas dimensões social e ambiental. Dentro da indústria química encontra-se o setor de produtos de higiene pessoal, perfumaria e cosméticos (HPPC), cujo faturamento no Brasil foi em 2012 de R \$ 34 bilhões, conforme dados da Associação Brasileira da Indústria de Higiene Pessoal, Perfumaria e Cosméticos - ABIHPEC (2013). Isso representa um crescimento de $250 \%$ em dez anos, devido principalmente a alguns fatores, como: (1) ascensão das classes C, D e E, favorecendo o incremento da demanda; (2) maior participação da mulher no mercado de trabalho; (3) aumento da competitividade em decorrência de avanços tecnológicos; (4) lançamento constante de novos produtos; e (5) aumento da expectativa de vida, o que induz ao consumo de cosméticos anti-idade. Destacam-se também o crescimento das exportações de setor e o acesso a novos mercados: entre 2003 e 2012, as exportações cresceram 186\% (de US\$ 295 milhões para US\$ 843 milhões) e o número de países de destino aumentou de 122 para 150 (ASSOCIAÇÃO..., 2013).

Apesar da importância econômica, as atividades desse setor exigem atenção no que concerne a aspectos ambientais. Segundo a Companhia de Tecnologia de Saneamento Ambiental (Cetesb) e a ABIHPEC, os principais impactos ambientais desse setor estão associados ao uso de água (incorporação aos produtos e limpeza e lavagem de equipamentos); uso de energia (etapas de aquecimento e resfriamento de itens em processo); uso de matérias-primas e produtos auxiliares tóxicos, irritantes ou corrosivos, gerando principalmente efluentes líquidos, solventes orgânicos, resíduos de embalagens e outros resíduos sólidos (sobras de produtos, produtos não conformes, produtos obsoletos, entre outros), além de emissões atmosféricas (COMPANHIA...; ASSOCIAÇÃO..., 2006). Por fim, relatório da ABIHPEC aponta como importantes tendências no setor aspectos relativos a biodiversidade, sustentabilidade socioambiental e apelo "vegetal" nos produtos, o que ratifica a importância de ações estratégicas ambientais nesse setor (ASSOCIAÇÃO..., 2011).

Considerando a relevância de atividades ambientais para a competitividade empresarial, bem como a importância de atitudes menos poluentes na indústria de HPPC, o objetivo proposto neste trabalho é a identificação e análise de estratégias ambientais implantadas por empresa de capital nacional atuante no setor em questão. Para tanto, além desta introdução, o trabalho é composto pelas seguintes seções: (a) método empregado no trabalho; (b) revisão teórica; (c) discussão dos resultados, com caracterização da empresa e análise do caso; (d) considerações finais; e (e) referências.

\section{Método}

Para que os objetivos deste trabalho pudessem ser cumpridos, foi realizada pesquisa de caráter qualitativo, utilizando como instrumento o método de estudo de caso em uma empresa nacional do setor de HPPC. $\mathrm{O}$ intuito foi verificar em que aspectos atividades de cunho ambiental desenvolvidas pela empresa estavam relacionadas à competitividade, considerando o alinhamento com questões estratégicas, a interação entre as áreas empresariais, as dificuldades e os resultados alcançados. Para tanto, foram empregados os seguintes procedimentos: (a) revisão de literatura sobre gestão ambiental, sistemas de gestão ambiental e estratégias competitivas; (b) elaboração e aplicação de roteiro de entrevista junto à empresa do setor de cosméticos; e (c) tratamento e análise das informações coletadas.

$\mathrm{O}$ roteiro de entrevista foi aplicado in loco, junto ao gerente de sistemas de gestão da empresa, contando com a colaboração de outros funcionários para 
respostas mais específicas. Além disso, as informações primárias foram complementadas a partir de fontes secundárias, tais como material institucional, relatórios anuais e balanços patrimoniais da empresa em estudo, obtidos tanto por intermédio dos entrevistados quanto por busca na internet.

Por fim, destaca-se que as informações foram tratadas por meio de análise de conteúdo, envolvendo a compreensão e interpretação das informações de fontes primárias e secundárias, indo além do conteúdo manifesto por meio de associações entre teoria e prática, conforme preconiza Godoy (1995).

\section{Competitividade e gestão ambiental}

O atual cenário competitivo é caracterizado pelo processo de globalização e por avanços tecnológicos acelerados, criando ambientes altamente dinâmicos e competitivos nos mais diversos setores. Em tal situação, as fontes convencionais de vantagem competitiva, como economias de escala, podem não se mostrar tão eficazes. Surge, assim, um novo paradigma, em que se destacam a flexibilidade estratégica, a perspectiva global, a inteligência competitiva e a inovação (HOSKISSON et al., 2009).

O manual de Oslo, em sua terceira edição, preconiza quatro tipos de inovação: (1) de produto (introdução de um bem ou serviço novo ou significativamente melhorado); (2) de processo (método de produção ou distribuição novo ou significativamente melhorado); de mercado (implementação de um novo método de marketing - concepção e embalagem de produto, posicionamento, promoção ou preço); e (4) organizacional (implementação de um novo método organizacional). As duas primeiras estão mais relacionadas a mudanças tecnológicas, enquanto as duas últimas são mais dependentes de mudanças comerciais e organizacionais (ORGANISATION..., 2005). Assim, assume-se a inovação como algo não necessariamente atrelado a avanços tecnológicos, mas sim a novas formas de produzir, organizar e vender.

Diante do contexto da globalização e da preocupação com questões ambientais, como com o aquecimento global, o conceito de desenvolvimento sustentável pode se tornar estratégico para a empresa. Nesse sentido, mudanças direcionadas para o uso mais eficiente dos recursos e para redução do impacto ambiental têm sido preconizadas, caracterizando o que se denomina eco-inovação, discutida em OECD (ORGANISATION..., 2009). Tais tipos de inovação são entendidos como aqueles que têm como resultado, intencionalmente ou não, a redução dos impactos ambientais. A análise das eco-inovações deve ocorrer sobre três dimensões: seu alvo (de produto, de processo, de mercado, organizacional ou institucional); os mecanismos (modificação, redesign, alternativa ou criação); e impactos (efeitos no meio-ambiente). As inovações têm papel crucial no direcionamento de empresas para a produção sustentável, implicando a integração de vários elementos em um sistema de inovação (ORGANISATION..., 2009).

Assim, uma adequada gestão ambiental passa a ter grande relevância no cenário competitivo empresarial. Sob o enfoque ambiental, alguns aspectos podem ser destacados. No que diz respeito à globalização, observa-se a crescente relevância não só da interdependência econômica de mercados, como também da interdependência ambiental, com destaque para o aquecimento global. No processo acelerado de mudanças tecnológicas, o alcance de vantagem competitiva pode estar atrelado a esforços inovativos guiados pelo contexto ambiental, seja por adequação regulatória ou antecipação a questões ambientais. Isso pode ocorrer pela criação de tecnologias para processos mais "limpos", tratamento de efluentes, utilização de resíduos, matérias-primas menos poluentes, entre outros. As organizações precisam considerar a importância de diferentes stakeholders na definição de estratégias, tais como governo, sociedade e comunidade local. Passa-se a considerar inclusive a abordagem multistakeholders, a partir de uma visão sistêmica e com ações envolvendo todas as partes interessadas (ELKINGTON, 2004).

Hoskisson et al. (2009) atentam para uma perspectiva recente da administração estratégica,em que predomina a orientação do comportamento empresarial tendo em vista os três diferentes grupos de stakeholders: do mercado de capitais, do mercado de produtos e organizacionais. Para os autores, o desempenho empresarial é multidimensional e a criação eficiente de valor deve ocorrer pelo equilíbrio do desempenho dos stakeholders, ponderando os conflitos entre diferentes grupos. Nesse sentido, o conceito de desenvolvimento sustentável pode se tornar estratégico para a empresa.

No que concerne ao aspecto estratégico da gestão ambiental, Porter e Van der Linde (1999), ao discorrerem sobre o possível dilema entre adequação ambiental e competitividade, afirmam que a necessidade de adequação ambiental deve impulsionar inovações que levem a maior competitividade das empresas. Segundo eles, deve-se eliminar o impasse ecologia versus economia à medida que a adoção de práticas ambientalmente corretas não está atrelada ao mero aumento dos custos. Para os autores, inovações desenvolvidas dentro do contexto da dinâmica competitiva podem proporcionar às organizações aumento da produtividade dos recursos, tornando-as mais competitivas. Assim, as empresas devem ampliar o enfoque, considerando o desperdício de recursos e de esforços de produção, bem como o comprometimento do valor do produto para o cliente associados à abordagem tradicional. 
O novo paradigma competitivo exige que a organização transforme as estratégias ambientais em assunto da alta gerência, incorpore o impacto ambiental na questão abrangente de aumento da produtividade e competitividade, direcionando o processo decisório pelo modelo da produtividade dos recursos e não pelo modelo de controle da poluição. Sob esse novo enfoque, competitividade econômica e incremento ambiental estão diretamente relacionados, uma vez que a inovação é capaz de melhorar a qualidade e simultaneamente promover a redução efetiva de custos (PORTER; VAN DER LINDE, 1999). Nesse sentido, novos conceitos têm emergido na área empresarial, com destaque para o que se denomina triple bottom line. Seguindo tal preceito, as organizações passam a preconizar a sustentabilidade e a medição do desempenho empresarial sob três aspectos: econômico, social e ambiental. Dentro de uma abordagem multistakeholder de geração de valor e competitividade, destaca-se a interação da organização com os sistemas econômico, social e natural (BROWN; DILLARD; MARSHALL, 2006).

Orsato (2002), ao discorrer sobre o posicionamento ambiental estratégico, afirma que a opção por estratégias para obtenção de melhor desempenho empresarial depende de alguns fatores, como a estrutura do setor em que atua, o posicionamento da empresa no setor, os tipos de mercado em que a empresa atua e suas competências internas. Considerando o foco competitivo - produto ou processo - e a fonte de vantagem competitiva - custo ou diferenciação, segundo tipologia de Porter (1991) - o autor ilustra que as estratégias ambientais podem ser direcionadas por: (a) aumento de produtividade dos recursos (foco em custo e processo) por meio, por exemplo, da reutilização de resíduos e da redução de perdas no processo; (b) liderança de custo ambiental (foco em custo e produto), por meio de inovações ambientais que possam gerar produtos com baixo custo econômico e/ou ambiental; (c) transcendência da conformidade legal (foco em diferenciação e processo), considerando, por exemplo, a implementação de Sistemas de Gestão Ambiental, tais como a norma ISO 14001; (d) produtos eco-orientados (foco em diferenciação e produto), gerando produtos que possam fornecer benefícios ambientais maiores ou proporcionar custos ambientais menores do que os dos concorrentes (ORSATO, 2002).

De acordo com North (1997), há diversos benefícios associados à gestão ambiental empresarial, como: (a) redução de custos, atrelada, por exemplo, ao uso racional de recursos (energia, matéria-prima etc.), à reciclagem de materiais e à fabricação de subprodutos; (b) aumento das receitas, decorrente de inovações em produtos e consequente aumento de market share, criação de novos mercados ou aumento de markup; (c) benefícios estratégicos, pela melhoria da imagem da empresa, renovação do portfólio de produto, aumento da produtividade, maior comprometimento e interação entre os funcionários, melhor relacionamento com autoridades públicas e comunidade, acesso mais fácil a mercados externos, entre outros.

Estudo empírico acerca da gestão ambiental de empresas no Brasil realizado por Jabbour et al. (2012) destacou que, mesmo em empresas certificadas pela ISO 14000 , a gestão ambiental é abordada de maneira preventiva, não sendo o desempenho ambiental central para vantagem competitiva. Apesar disso, os autores mostraram que a gestão ambiental contribuiu para ganhos de desempenho nos fatores competitivos prioritários, custo, qualidade, flexibilidade e entrega para as empresas, indicando a importância da gestão ambiental bem como a necessidade de adoção de postura mais proativa, por exemplo, no desenvolvimento de produtos e nos relacionamentos colaborativos entre os agentes da cadeia de suprimentos.

Barbieri (2011) aponta três perspectivas da gestão ambiental empresarial: controle da poluição, prevenção da poluição e visão estratégica. Essa última, para o autor, trata de uma abordagem mais avançada, em que prevalecem ações proativas e antecipatórias, com envolvimento permanente e sistemático da alta gerência, para alcance de vantagens competitivas e incremento da competitividade. Dentro de tal abordagem estratégica devem existir atividades ambientais disseminadas por toda a organização e ampliação de ações e práticas ambientais ao longo de toda a cadeia produtiva. A empresa, nesse caso, deve buscar alavancar oportunidades de mercado e neutralizar ameaças decorrentes de questões ambientais. Assim, a adoção da abordagem estratégica depende exatamente da existência de tais oportunidades e/ou ameaças no mercado em que a organização está inserida.

As estratégias de atuação na área ambiental podem ocorrem em diferentes níveis, conforme estudo da FIESP/CIESP (FEDERAÇÃO...; CENTRO..., 2006). Em um estágio inicial, para sobrevivência empresarial, a empresa deve buscar a conformidade legal, que corresponde ao atendimento às exigências legais. Um segundo estágio, de conformidade normativa, diz respeito ao atendimento voluntário a normas técnicas ambientais de gestão e de processo, com eventuais certificações, importante para posicionamento competitivo no mercado. Em um terceiro estágio, a empresa pode adotar postura gerencial proativa e abordar a questão ambiental de maneira integrada, considerando a avaliação dos impactos no meio ambiente, a mensuração dos custos ambientais e o princípio de melhoria contínua, buscando a ecoeficiência por meio, por exemplo, da adoção de tecnologias mais limpas. Por fim, o econegócio corresponde ao quarto estágio de conformidade 
ambiental, em que a empresa busca inserir-se em mercados ambientalmente responsáveis, com pesquisa, geração e fornecimento de produtos sustentáveis desenvolvidos a partir de avanços tecnológicos significativos para a preservação ambiental, cujo intuito é estimular, intensificar ou expandir os negócios ambientalmente responsáveis. Inclui-se nesse último estágio fomento à biodiversidade e criação e participação em comitês para a sustentabilidade (FEDERAÇÃO...; CENTRO..., 2006).

A partir de uma revisão de literatura, Souza (2002) mostra que a gestão ambiental tem passado por um processo evolutivo nas organizações. Em maior ou menor grau, tem-se evoluído de uma postura mais reativa, em um "modelo de conformidade" no qual a questão ambiental é considerada uma ameaça, para uma postura mais proativa, dentro de um "modelo estratégico" em que as empresas enxergam aspectos ambientais como oportunidades de negócio. São condicionantes de tal dinâmica alguns fatores organizacionais, como governo, concorrentes, mercado, instituições e fornecedores, bem como o tipo de resposta de cada empresa. O autor afirma que a evolução nas estratégias ambientais nas empresas é, em geral, decorrente de: (a) regulamentação; (b) pressão da sociedade civil; (c) condições de mercado - consumidores ambientalmente mais atentos e concorrência acirrada; e (d) recursos escassos - água, energia, dinheiro etc.

Recentemente tem-se destacado o consumidor como importante stakeholder no processo de adequação sustentável das empresas. Instituto Akatu e Instituto Ethos (2010), ao discorrerem sobre percepções e expectativas do consumidor brasileiro sobre a responsabilidade social das empresas (RSE), apontam algumas práticas ambientais destacadas como relevantes pelos consumidores. Dentre elas encontram-se: (a) a promoção de programas de informação ou educação de consumidores sobre os impactos sociais e ambientais relativos a hábitos de consumo; (b) investimento em novas tecnologias que permitam a reciclagem pós-consumo; (c) manter programas para racionalização e otimização do consumo de água e energia; e (d) incluir critérios de responsabilidade social em seus processos de seleção e avaliação de fornecedores.

Segundo o mesmo estudo, para $65 \%$ dos consumidores entrevistados a construção de uma imagem de empresa socialmente responsável depende da adoção de práticas ambientais, que incluem gestão de impactos ambientais, inovações tecnológicas e emissão de gases de efeito estufa (GEEs). Nesses aspectos, o estudo aponta forte discrepância entre as expectativas do consumidor e as ações de empresas brasileiras, pois apenas $35 \%$ das empresas entrevistadas adotam tais tipos de prática (INSTITUTO...; INSTITUTO..., 2010).
De acordo com Andrade (1997), em busca de se adequar ao novo padrão competitivo, associado às exigências da consideração de aspectos ambientais na definição de estratégias, as empresas podem se posicionar em três estágios estratégicos distintos: (a) estratégia reativa, atendendo minimamente e de maneira relutante a uma legislação ambiental vigente e encarando adequações ambientais como custosas e sem retorno financeiro; (b) estratégia ofensiva, buscando antecipar-se aos concorrentes por meio da redução da poluição e do uso de recursos ambientais, além do exigido por lei, via mudanças incrementais em processos e produtos, percebendo, portanto, a questão ambiental como fonte de vantagem competitiva; e (c) estratégia inovativa, antecipando-se aos problemas ambientais futuros, buscando a excelência ambiental, a inovação em produtos e processos e a vinculação de questões ambientais à estratégia corporativa (ANDRADE, 1997).

Destacando a relevância de mecanismos de política pública que incentivem os esforços de melhoria ambiental, Porter e Van der Linde (1999) afirmam que a regulamentação ambiental apresenta implicações competitivas, o que foi ratificado empiricamente por outros estudos, conforme destacado em Iraldo et al. (2009). Para Porter e Van der Linde (1999), uma minoria de empresas apresenta postura proativa de inovação para melhoria ambiental, sendo mais frequente a observância de inovação para adequação ambiental em resposta a mecanismos regulatórios. Assim, a regulamentação é importante para impulsionar tais inovações. Isso se deve a algumas razões, como: pressão sobre as empresas para geração de inovações; melhoria da qualidade ambiental; alerta às empresas sobre o uso ineficiente dos recursos e a necessidade de aprimoramento tecnológico; incentivo às inovações ambientalmente corretas; promover equilíbrio competitivo, garantindo que empresas não criem vantagem competitiva a partir de ações agressivas ao meio ambiente (PORTER; VAN DER LINDE, 1999).

A questão ambiental pode estar atrelada a estratégias empresarias em diversos aspectos. A geração de vantagem competitiva em custo, por exemplo, pode depender da adoção de práticas para melhorias ambientais que permitam economia de materiais, maiores rendimentos do processo, melhor utilização de subprodutos, menor consumo de energia e água, redução do custo de embalagens, redução dos custos de descarte, entre outros. Estratégias de diferenciação, por sua vez, podem ser alavancadas pela geração de produtos ambientalmente corretos e a adoção de selos que certifiquem tais características, quando esse é atributo valorizado pelos clientes e reflete melhor imagem da marca (ALIGIERI; ALIGIERI; KRUGLIANSKAS, 2009; JABBOUR et al., 2012). 
Conforme destacado por Martín-Tapia, AragónCorrea e Rueda-Manzanares (2010), estratégias ambientais proativas podem favorecer a inserção internacional de negócio. Em estratégias de internacionalização, a adoção de melhorias ambientais é relevante, à medida que (a) consumidores de mercados almejados podem valorizar práticas ambientais, representando um atributo relevante; (b) a exigência de produtos e processos ambientalmente corretos é frequente em muitos países, caracterizando muitas vezes barreiras à exportação.

Processos de diversificação também podem ser impulsionados por práticas de cunho ambiental: pode-se promover a diversificação pela produção a partir de resíduos antes descartados, aumentando o portfólio de produtos e/ou criando novas linhas de produtos. Por fim, empresas que atuam em ambiente altamente inovativo e/ou que adotam a inovação como estratégia foco podem fazem uso de práticas ambientais associando a inovação a melhorias ambientais. Para Forsman (2013), estratégias de inovação ambiental estão diretamente relacionadas a incrementos de competitividade das firmas, principalmente aquela direcionada a ganhos de desempenho de mercado, eficiência, redução de riscos e à imagem/reputação.

Assim, fica claro que vantagens associadas à adoção de práticas ambientalmente corretas pelas empresas é fato presente e que pode ser identificado em diversos setores. Tais vantagens podem ser oriundas de stakeholders diversos. Instituições financeiras, por exemplo, disponibilizam crédito com menores taxas de juros para empresas que comprovadamente possuem projetos de redução do impacto ambiental negativo de suas atividades. Além disso, a Bolsa de Valores de São Paulo (Bovespa) utiliza um índice para verificar a sustentabilidade de empresas (ISE) que consiste em medida de desempenho empresarial que considera a sustentabilidade corporativa baseada na eficiência econômica, no equilíbrio ambiental, na justiça social e na governança corporativa (FUNDAÇÃO..., 2011). A partir desse índice há a sinalização e consequentemente valorização das ações de empresas que causam menor impacto negativo no meio ambiente (MACEDO et al., 2012).

Outro aspecto relacionado à competitividade para empresas "amigas do meio ambiente" é a possibilidade de comercialização de créditos de carbono. Através desse mecanismo, empresas que lançam na atmosfera GEEs como: dióxido de carbono $\left(\mathrm{CO}_{2}\right)$; monóxido de carbono (CO), metano $\left(\mathrm{CH}_{4}\right)$, entre outros, têm a possibilidade de reduzir seu impacto negativo comprando créditos de carbono de outras empresas. Isso significa que empresas que mais absorvem GEEs do que os lançam no meio ambiente podem vender o "direito de poluir" (créditos de carbono) às demais. Portanto, a venda de créditos de carbono pode representar fator de incremento à competitividade para empresas ambientalmente corretas, elevando receita (SCHULTZ; WILLIAMSON, 2005).

Santin (2007) aponta que as principais vantagens potenciais para as empresas podem ser ganhos financeiros e preservação ambiental. A adequação à legislação ambiental, ou seja, estar de acordo com a legislação ambiental vigente, evita o pagamento de multas e/ou outras penalidades para a empresa, além de criar maior reputação e melhor imagem junto a clientes e sociedade.

Considerando a gestão ambiental estratégica ao longo da cadeia de suprimentos, de acordo com Mollenkopf et al. (2010), estratégias ambientais de cadeia de suprimentos (Green Supply Chain Strategies - GSCS) são aquelas relativas a esforços para minimização dos impactos negativos de firmas e suas cadeias de suprimentos no meio ambiente. Em termos amplos, os mecanismos de gestão sustentável da cadeia de suprimentos estão relacionados à obtenção de melhor desempenho ambiental, melhorando a cadeia de valor. Para alavancar vantagem competitiva, faz-se necessário o estabelecimento de alianças e parcerias entre os agentes da cadeia, dado que a abordagem de gestão da cadeia de suprimentos está relacionada a complexidade, sinergia e interações de longo prazo.

Nesse contexto, dois aspectos podem ser destacados. Primeiramente, a montante da cadeia, a consideração da perspectiva ambiental para seleção e melhoria de fornecedores. O incentivo e a valorização de práticas ambientalmente corretas dos fornecedores pode favorecer a própria gestão ambiental interna,à medida que facilita a obtenção de processos mais limpos, produtos menos agressivos ao meio ambiente, redução de descartes, melhor imagem da marca, entre outros. A jusante da cadeia, por sua vez, a logística reversa pode representar importante mecanismo de gestão ambiental (MOLLENKOPF et al., 2010).

Segundo Novaes (2007), a logística reversa trata dos fluxos de materiais desde os pontos de consumo até seus pontos de origem, tendo como objetivos recuperar valor e/ou proporcionar disposição adequada aos materiais. Trata-se de atividades pós-consumo ou pós-venda, permitindo redução de custos em decorrência de economia de matérias-primas e reaproveitamento de materiais, cumprimento da regulamentações (ex.: coleta de embalagens de agrotóxicos), além de alavancar marketing ambiental (green marketing) e melhorar a imagem da empresa.

Fica claro, portanto, que o surgimento de um novo cenário competitivo traz a necessidade de adoção de novas posturas pelas empresas, permitindo alavancagem de vantagem competitiva sustentável a partir de oportunidades relacionadas a melhorias ambientais. Dentro de um contexto de gestão ambiental estratégica, organizações podem fazer uso de diversas práticas ambientais, considerando os mais distintos stakeholders e gerando vários benefícios, podendo 
inclusive associar aspectos ambientais a ganhos financeiros e aumento de competitividade.

\section{Discussão dos resultados}

\subsection{Caracterização da empresa}

Fundada no final da década de 1960, trata-se de uma empresa de capital nacional e aberto. Atuante no setor de higiene pessoal, perfumaria e cosméticos, a empresa em análise contava, em 2010, com 5.900 funcionários e cinco principais linhas de produtos, sendo uma delas com forte apelo ambiental e social.

Com relação à atuação, 94\% de suas vendas são direcionadas ao mercado interno, em alcance nacional, e o restante comercializado em mercados latino-americanos e europeus. Segundo o entrevistado, a empresa tem trabalhado em processo de expansão de mercado, buscando aumento de market share. De acordo com dados da Associação Brasileira da Indústria de Higiene Pessoal, Perfumaria e Cosméticos, a receita líquida do setor apresentou crescimento de 14,7\% entre 2008 e 2009 (ASSOCIAÇÃO..., 2010). Para a empresa entrevistada, esse crescimento foi mais expressivo, implicando aumento de $18,6 \%$ no mesmo período.

A expansão também se dá via estratégia de internacionalização, buscando a consolidação da marca em novos mercados, parte de países europeus, e o aumento de market share em mercados internacionais já consolidados, como em países da América Latina. Entre 2008 e 2009, a receita bruta no mercado interno apresentou aumento de $18 \%$, enquanto a receita bruta no mercado externo cresceu $37 \%$ no mesmo período.

Em termos de estratégia e concorrência, a empresa destaca a inovação como fator-chave de sucesso, atrelada à agregação de valor. Nesse sentido, a linha de produtos com forte apelo ambiental e social é destacada como a mais relevante para a empresa, em termos de aposta estratégica, especialmente por representar, segundo o entrevistado, "[...] uma das maiores expressões de nossa essência.” Está entre os compromissos assumidos pela empresa a geração de valor para a sociedade por meio da integração de fatores econômicos, sociais e ambientais, preconizando a abordagem triple bottom line. Faz-se, portanto, uma conexão entre a aposta da empresa em termos estratégicos e o próprio comportamento empresarial.

$\mathrm{O}$ entrevistado destacou duas grandes empresas multinacionais como principais concorrentes, afirmando que a atuação estratégica delas está mais relacionada, para uma delas, à identificação das submarcas à "marca mãe" e, para outra, à redução de custos e otimização de processos. De acordo com o entrevistado, o diferencial estratégico da empresa, tendo a inovação como foco central de sua estratégia, é a agregação de valor e a construção de identidades próprias para submarcas. Assim, a empresa tem caminhado em um processo de diferenciação, o que lhe permite inclusive explorar maior potencial de suas linhas de produto.

\subsection{Gestão ambiental na empresa}

De acordo com o estudo, a questão ambiental está claramente associada à estratégia empresarial, o que é comprovado em vários aspectos. Primeiramente, destaca-se que a missão, a visão e os valores da empresa em estudo estão fortemente associados a aspectos ambientais, destacando-se a interação do homem com o meio ambiente. A empresa possui uma política ambiental formalizada, incluindo diretrizes ambientais no planejamento estratégico empresarial, as quais tratam de temas como biodiversidade, impacto de produtos e GEEs, dentre outros. Destaca-se também que a empresa conta com uma diretoria voltada para a sustentabilidade e cujo principal papel é garantir o equilíbrio entre as áreas social, econômica e ambiental, promovendo uma abordagem transversal sobre a importância de incluirem-se indicadores e metas ambientais e sociais nas atividades estratégicas, táticas e operacionais desenvolvidas na empresa. Outro aspecto importante é que os investimentos em meio ambiente passaram de menos de $6 \%$ do total de investimentos, em 2007, para mais de $17 \%$, em 2009. De acordo com o entrevistado, a empresa não trata os recursos financeiros direcionados para a área ambiental como custos, mas sim como investimentos, pois devem proporcionar retorno para a empresa, segundo o preceito triple bottom line.

No que concerne à gestão ambiental, a empresa implementou Sistema de Gestão Ambiental e se certificou, em 2004, na ISO 14001, antes mesmo de obter certificação ISO 9001. A adoção do sistema de gestão da qualidade (ISO 9001) surgiu pela necessidade de melhor estruturação dos processos internos, principalmente em decorrência do aumento e complexidade de operações. A certificação ambiental foi motivada pelo desejo de comprovar junto a clientes e fornecedores que a proposta de sustentabilidade é de fato adotada pela empresa. De acordo com o entrevistado, a certificação ambiental é "[...] uma forma de mostrar aderência ao discurso ambiental." Destaca-se que, atualmente, a empresa possui um sistema integrado de gestão, que engloba normas ambientais e de qualidade e que inclui a visão de ecoeficiência ao longo da cadeia de valor, junto a fornecedores e pelos canais de distribuição, por exemplo.

Para alcançar melhor desempenho competitivo dentro do preceito triple bottom line, especificamente no que concerne ao pilar ambiental, a empresa tem formalizada uma política ambiental que busca contextualizar suas atividades no sistema natural/ 
meio ambiente, minimizando os impactos negativos e amplificando os impactos positivos. Para tanto, segundo o entrevistado, adota um conjunto de ações e projetos, destacando-se uma política de sustentabilidade que contempla as seguintes diretrizes:

- Adoção dos princípios de sustentabilidade, incluindo a questão ambiental em seu planejamento estratégico, dentro de um processo de melhoria contínua;

- Educação ambiental, ao disseminar internamente a cultura de responsabilidade ambiental e ao estabelecer compromissos e parcerias com fornecedores;

- Gerenciamento de impactos ambientais e avaliação de ciclo de vida (ACV) de produtos e serviços, com foco em ações preventivas e realização de atividades de monitoramento e controle. A ACV constitui ferramenta de gestão ambiental que possibilita verificar o impacto potencial ao meio ambiente a partir do uso e transformações de recursos e materiais ao longo da cadeia, desde a extração da matéria-prima até a disposição final do produto;

- Minimização de entrada e saída de materiais, buscando redução do consumo de água, energia, produtos tóxicos e matérias-primas, bem como destinação apropriada de resíduos.

\subsubsection{Procedimentos para gestão ambiental}

Para que os objetivos traçados na política de gestão ambiental da empresa pudessem ser alcançados, os seguintes procedimentos adotados foram destacados:

- Redução do impacto ambiental negativo de produto. Essa prática foi implantada em 2005, visando a redução do impacto negativo dos produtos fabricados pela empresa. Em 2009, $79,2 \%$ dos produtos gerados pela empresa tinham como matérias primas fontes renováveis vegetais. Além disso, a empresa havia eliminado componentes químicos controversos de mais de $90 \%$ de seus produtos. Ressalta-se que essa prática está formalmente definida na política de sustentabilidade da empresa.

- Redução do impacto ambiental negativo de processo. A empresa realiza a gestão de resíduos nos processos, buscando a evolução nos processos de sua destinação e a priorização da reciclagem de resíduos do processo produtivo. A partir do programa de gestão de resíduos, cuja implantação iniciou-se em 2000, a empresa conseguiu reduzir a quantidade de resíduos sólidos gerada por unidade de produto em cerca de $10 \%$, entre 2007 e 2009 associada à redução da participação dos resíduos Classe I (resíduos perigosos). Nessa classificação incluem-se produtos cosméticos obsoletos, resíduos ambulatoriais e de laboratório, álcool, óleo lubrificante e resíduos de manutenção. Além disso, no mesmo período a empresa aumentou o percentual de resíduos reciclados de $88 \%$ para 91,5\%, em detrimento da incineração ou destinação a aterros.

- Utilização de recursos naturais menos impactantes em substituição aos insumos químicos. Essa prática está formalmente definida na política de sustentabilidade da empresa, tendo sido adotada em 2007 com objetivo de privilegiar a saúde humana e ambiental. Entre as medidas adotadas, optou-se pela utilização do álcool orgânico em substituição ao álcool comum para a fabricação dos produtos.

- Redução do impacto ambiental negativo pós-consumo. Com essa medida e com a metodologia adotada pelas normas da ISO 14000 referentes à avaliação de ciclo de vida do produto (ACV), a empresa tem por objetivo a redução do impacto ambiental das embalagens dos produtos. Para tanto, consideram-se os impactos causados desde a fase de extração dos materiais até a disposição final, passando por processamento e transporte. Destaca-se o pioneirismo tanto na década de 1980 , com o lançamento de produtos em refis no setor de atuação, bem como recentemente, com a adoção de embalagens de "plástico verde" em refis de seus produtos. O "plástico verde" consiste em polímero fabricado a partir de matéria-prima vegetal $100 \%$ renovável e está associado à diminuição das emissões de GEEs. A empresa afirma ainda (a) incentivar a venda de produtos em refis, dado que esses têm menor impacto ambiental e são 100\% recicláveis (em 2009 , cerca de $15 \%$ dos produtos ofereciam a possibilidade de refil); (b) utilizar embalagens de PET (polietileno) reciclado em seus produtos; e (c) promover o recolhimento e destinação apropriados para as embalagens pós-consumo, por meio de parceria com transportadores, para entrega a cooperativas de catadores locais. Em 2009 foram recolhidas 120 toneladas de embalagens pós-consumo, um aumento de $32 \%$ em relação a 2007, ano de implantação do projeto. Além disso, o impacto ambiental das 
embalagens, por quantidade de produto, sofreu uma redução de mais de 5\% entre 2007 e 2009.

- Uso racional de recursos naturais não renováveis. Esse procedimento é colocado em prática por meio de duas principais iniciativas: (a) redução do consumo e reciclagem e reutilização da água; (b) redução do consumo de energia e priorização do uso de energia de fontes renováveis (ex. hidrelétrica) em suas atividades. Tais melhorias dependem de adequações infraestruturais, bem como de adaptações de processos. Em termos corporativos, entre 2005 e 2009, a empresa reduziu o consumo de água por unidade em mais de $10 \%$, e o consumo de energia em $11 \%$. Considerando suas duas principais plantas produtivas, entre 2007 e 2009 houve uma redução de mais de $20 \%$ no consumo de água e de $31,5 \%$ no consumo de energia.

- Certificação de ativos. Essas medidas são referentes principalmente à criação de programas de certificação de matérias-primas vegetais e dizem respeito à sustentabilidade socioambiental, buscando assegurar manejo tradicional, boas práticas agrícolas, produção orgânica, agricultura sustentável, entre outros. A motivação para adoção dessa prática está relacionada à percepção da necessidade de uso adequado dos recursos da biodiversidade ao longo da cadeia, bem como à busca por rastreabilidade das matériasprimas. Entre 2005 e 2009, a empresa dobrou o número de ativos certificados. Em termos de porcentagem do total de espécies certificados, a empresa passou de 46\%, em 2005, para 58\%, em 2009. Ressalta-se a importância da parceria da empresa com seus fornecedores para fomento de tais práticas, implicando a necessidade de mecanismos de gestão ao longo da cadeia.

- Formação de consciência ambiental no consumo. A empresa, segundo entrevistado, entende que deve estimular o consumo consciente, despertando no cliente o conhecimento do impacto de suas escolhas sobre o meio-ambiente, a sociedade e si mesmo. Para tanto, a empresa faz uso de selos de certificação em seus produtos, indicando a origem das matérias-primas, bem como divulga tabela ambiental nas embalagens dos produtos. Tais tabelas apresentam informações sobre a origem e o impacto ambiental do conteúdo e das embalagens daquele produto, permitindo ao consumidor identificar, por exemplo, o percentual de componentes de origem renovável vegetal e o uso de materiais reciclados e recicláveis no produto. Mesmo que indiretamente, tais ações estão ligadas ao marketing ambiental da empresa, sendo esse alavancado principalmente por trabalhos de divulgação, comunicação e promoção de produtos com apelo ambiental.

- Programa Carbono Neutro. Redução das emissões de GEEs e compensação das emissões por meio de projetos de caráter socioambiental para captura de carbono e promoção de ganhos sociais. Para tanto, uma série de ações têm sido adotadas, como: (a) alterações logísticas, com melhor gestão de distribuição, roteirização e carregamentos e substituição de modais logísticos pelos menos poluentes; (b) substituição ou eliminação de embalagens de matérias-primas; (c) redução do uso de energia, entre outras. Como projetos de compensação, destacam-se a restauração florestal e a recuperação de matas ciliares e nascentes. A empresa enfatiza que, desde 2007, ano de implantação do projeto, houve redução de $16 \%$ nas emissões de GEEs.

Cabe destacar que os procedimentos ambientais listados não tinham como principal motivação a redução de custos. $\mathrm{O}$ foco das melhorias ambientais, para a empresa, está relacionado à geração de valor ambiental, sendo a redução de custos, quanto presente, consequência paralela. Em grande parte, a busca por maior market share pela empresa está associada à agregação de valor e construção da imagem da marca, fortemente dependente de ações ambientais. A Figura 1 ilustra os procedimentos relatados no estudo, bem como os potenciais ganhos de competitividade associados a tais melhorias ambientais, destacando que eles têm caráter econômico, ambiental e social.

Os resultados podem estar diretamente associados à redução de custos (no caso de adequação ambiental, podem-se reduzir custos decorrentes de multas ambientais), à inserção de novos produtos no mercado, à entrada em novos mercados, à melhoria da imagem da marca e consequente resultados em vendas, dentre outros. Ressalta-se também a interação entre os resultados de melhorias ambientais. Entende-se, por exemplo, que alguns procedimentos podem estar relacionados a marketing verde, o que favorece a imagem da marca e a consequente agregação de valor, permitindo margens de lucro maiores e/ou aumento de receitas (maior market share ou conquista de novos mercados); outros procedimentos, por sua vez, podem estar associados à coordenação sustentável da cadeia de suprimentos (Green SCM), o que pode resultar em redução de custos e agregação de valor.

A Figura 1 indica ainda a relação entre os procedimentos destacados e o tipo de inovação. Assim, a redução do impacto ambiental negativo pós-consumo 

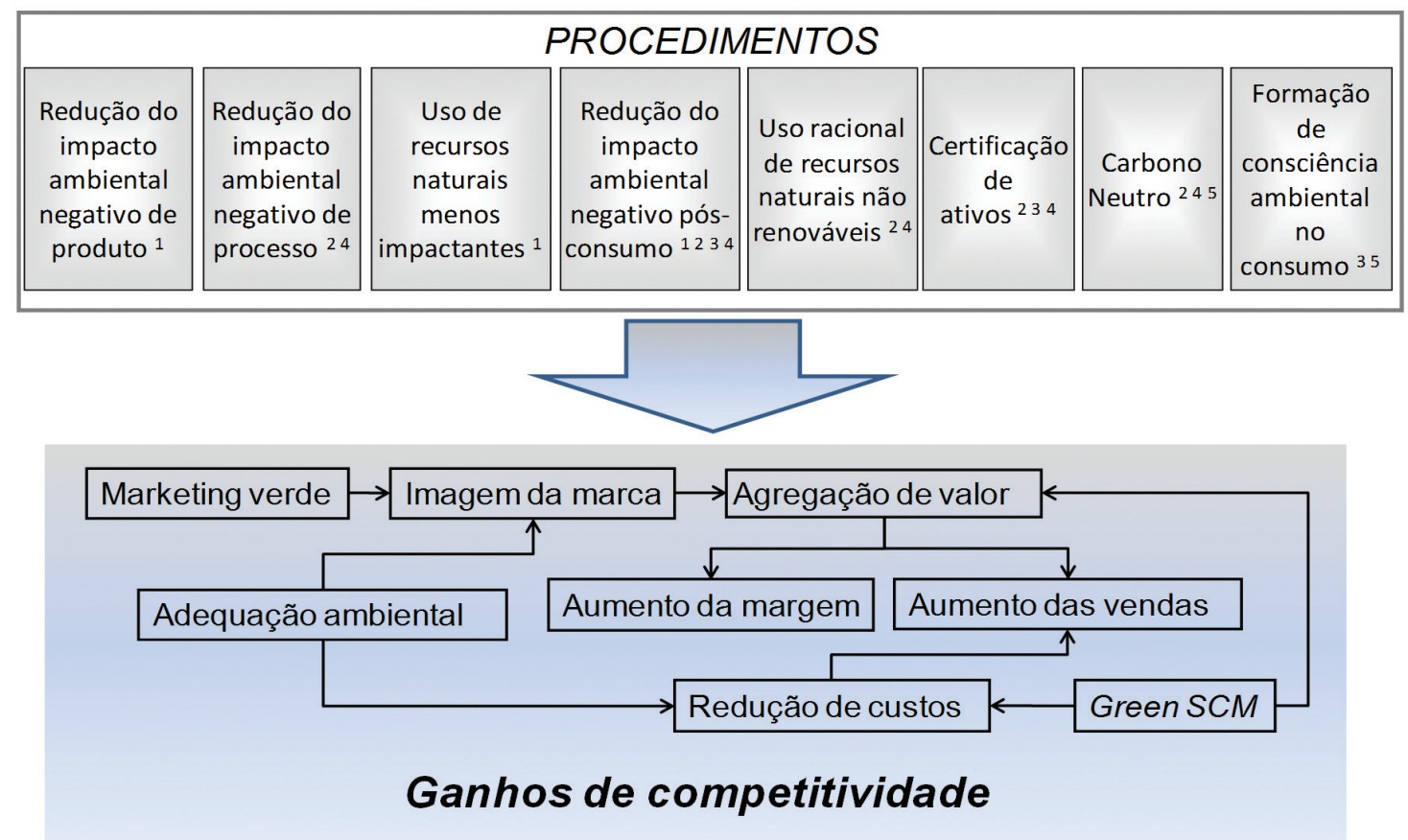

Tipos de inovação:

1 Produto

2 Processo

3 Marketing

4 Organizacional

5 Institucional

Figura 1. Procedimentos ambientais e ganhos de competitividade. Fonte: elaborada pelos autores.

está atrelada a inovações de produto (alterações de embalagem); inovações em processo (novas formas de distribuição); inovações de marketing (novos conceitos de produto); inovações organizacionais (ISO 14000 e ACV) e inovações institucionais (retorno de embalagens depende de alterações de valores dos consumidores).

\subsection{2 Áreas envolvidas}

Todos os procedimentos acima listados foram realizados a partir de iniciativa da alta gerência, incluindo vice-presidências e diretorias. Assim, algumas considerações importantes podem ser feitas. Primeiramente, pôde-se constatar que as ações de caráter ambiental são tomadas na empresa segundo uma perspectiva topdown, a partir da alta gerência, o que condiz com a postura de tratar as questões ambientais em nível estratégico. De acordo com o Quadro 1, de uma maneira geral observa-se que as ações relativas a alterações/inovações de produtos são alavancadas pela alta gerência de inovação de produtos, também diretamente ligada com as ações pós-consumo e os programas de certificação de matérias-primas. A alta gerência de operações e logística também tem papel relevante na implantação e condução de procedimentos para gestão ambiental, sendo diretamente responsável por alterações em processos, tais como gestão de resíduos e racionalização do uso de recursos naturais não renováveis. Por fim, projetos mais abrangentes, como os projetos Carbono Neutro e Tabela Ambiental, são de responsabilidade da diretoria de sustentabilidade.

Além disso foi relatada a interação de diferentes áreas na condução dos procedimentos listados (Quadro 1). Percebe-se que a implantação de todos os procedimentos listados dependeu da interação entre áreas empresariais. Destaca-se também a importância da participação de todas as áreas internas para a condução de vários procedimentos, bem como a relevância da diretoria de sustentabilidade, presente em todos os procedimentos (seja como área indutora seja como área envolvida).

Por fim, fica clara a importância da formação de parcerias com agentes externos para condução dos procedimentos de melhoria ambiental. De maneira geral, as atividades que envolveram coleta, tratamento e/ou destinação apropriada de resíduos necessitaram de alguma articulação na cadeia de suprimentos, principalmente com fornecedores e coletores de resíduos. As atividades relativas à inovação de produto, por sua vez, dependeram de parcerias em pesquisa e desenvolvimento e fornecimento de insumos. Por fim, procedimentos mais amplos, como o Carbono Neutro, foram alavancados por meio de parceria com consultoria, dada a necessidade de conhecimento técnico específico e imparcialidade nas avaliações. 
Quadro 1. Gestão ambiental: procedimentos, iniciativa e outras áreas envolvidas.

\begin{tabular}{|c|c|c|c|c|}
\hline Procedimentos & Ações & Área indutora & Áreas envolvidas & $\begin{array}{c}\text { Agentes externos } \\
\text { parceiros }\end{array}$ \\
\hline $\begin{array}{l}\text { Redução do impacto } \\
\text { ambiental do produto }\end{array}$ & ACV/ecodesign & Inovação de produtos & $\begin{array}{c}\text { Diretoria de } \\
\text { sustentabilidade }\end{array}$ & -- \\
\hline $\begin{array}{l}\text { Redução do impacto } \\
\text { ambiental negativo } \\
\text { do processo }\end{array}$ & $\mathrm{ACV} / \mathrm{P}+\mathrm{L}$ & Operações e logística & $\begin{array}{l}\text { Todas as áreas } \\
\text { internas }\end{array}$ & $\begin{array}{c}\text { Intermediários } \\
\text { coletores de resíduos } \\
\text { recicláveis }\end{array}$ \\
\hline $\begin{array}{l}\text { Uso de recursos } \\
\text { naturais menos } \\
\text { impactantes }\end{array}$ & ACV/ecodesign & Inovação de produtos & $\begin{array}{c}\text { Diretoria de } \\
\text { sustentabilidade }\end{array}$ & Fornecedor \\
\hline $\begin{array}{l}\text { Redução do impacto } \\
\text { ambiental negativo } \\
\text { pós-consumo }\end{array}$ & $\begin{array}{l}\text { ACV/ecodesign/ } \\
\text { GSCS (estratégias de } \\
\text { pós-consumo) }\end{array}$ & Inovação de produtos & $\begin{array}{c}\text { Diretoria de } \\
\text { sustentabilidade } \\
\text { Planejamento } \\
\text { mercadológico } \\
\text { Diretoria de serviços } \\
\text { ao cliente }\end{array}$ & $\begin{array}{l}\text { Parceiro para } \\
\text { desenvolvimento } \\
\text { de produto; rede } \\
\text { de catadores de } \\
\text { resíduos; ONG para } \\
\text { desenvolvimento } \\
\text { sustentável; } \\
\text { fornecedor de PET }\end{array}$ \\
\hline $\begin{array}{l}\text { Uso racional de } \\
\text { recursos naturais não } \\
\text { renováveis }\end{array}$ & $\begin{array}{c}\mathrm{P}+\mathrm{L} \text { (redução na } \\
\text { fonte e reciclagem } \\
\text { interna) }\end{array}$ & Operações e logística & $\begin{array}{l}\text { Todas as áreas } \\
\text { internas }\end{array}$ & -- \\
\hline Certificação de ativos & $\begin{array}{c}\text { GSCS } \\
\text { (desenvolvimento de } \\
\text { fornecedores) }\end{array}$ & Inovação de produtos & $\begin{array}{c}\text { Diretoria de } \\
\text { sustentabilidade }\end{array}$ & -- \\
\hline $\begin{array}{l}\text { Formação de } \\
\text { consciência } \\
\text { ambiental no } \\
\text { consumo }\end{array}$ & Rotulagem ambiental & $\begin{array}{c}\text { Diretoria de } \\
\text { sustentabilidade }\end{array}$ & $\begin{array}{l}\text { Todas as áreas } \\
\text { internas }\end{array}$ & -- \\
\hline Carbono Neutro & $\mathrm{ACV} / \mathrm{P}+\mathrm{L}$ & $\begin{array}{c}\text { Diretoria de } \\
\text { sustentabilidade }\end{array}$ & $\begin{array}{l}\text { Todas as áreas } \\
\text { internas }\end{array}$ & $\begin{array}{c}\text { Empresa de } \\
\text { consultoria e } \\
\text { avaliação ambiental }\end{array}$ \\
\hline
\end{tabular}

Fonte: elaborado pelos autores.

\subsubsection{Principais dificuldades}

No que concerne às dificuldades para implantação dos procedimentos listados, o entrevistado apontou que elas dizem respeito principalmente a:

- Elevados investimentos: o entrevistado aponta como procedimentos associados a essa limitação aqueles que envolvem inovações de produto e/ ou de processo;

- Estruturação e gestão da cadeia de suprimentos: mesmo na presença de parcerias com agentes a montante e a jusante da cadeia, o entrevistado afirmou que a necessidade de coordenação entre os agentes para, por exemplo, adquirir materiais menos poluentes ou providenciar a coleta de resíduos de processo recicláveis muitas vezes dificulta a implantação e condução de algumas práticas ambientais;

- Conhecimento técnico e científico: ainda que a empresa possa contar com parcerias para inovação de produto, o desenvolvimento de novas fórmulas e adequações de novas embalagens são fatores apontados como importantes dificuldades encontradas;

- Descontinuidade de linhas e velocidade de inovação: especialmente no que diz respeito à certificação de ativos, o entrevistado destacou como grandes dificuldades o fato de que as linhas de produtos cujas matérias-primas alcançam certificação serem descontinuadas com certa rapidez para dar lugar a novos produtos/linhas. Se, por um lado, isso se torna necessário pela necessidade de lançamento de novos produtos no mercado, por outro acaba por ser fator desfavorável ao processo de certificação, que demanda tempo e recursos financeiros;

- Dificuldades de caráter social: essas estão presentes nas situações em que a prática ambiental depende fortemente da conscientização de stakeholders, como consumidores, colaboradores, fornecedores e coletores de resíduos;

- Dificuldades de caráter legal: essas dizem respeito tanto a exigências quanto a limitações 
legais. O entrevistado destacou as dificuldades legais associadas à logística reversa para condução do projeto de recolhimento e destinação das embalagens pós-consumo. Nesse caso, em 2008, a Lei Municipal de Resíduos Sólidos de São Paulo obrigou as empresas do setor a providenciar a logística reversa das embalagens dos produtos, o que exigiria grande comprometimento do elo varejo e dos consumidores. A empresa espera que a regulamentação da Política Nacional de Resíduos Sólidos (PNRS), em 2010, facilite a consolidação desse sistema, viabilizando tais práticas, dado que deve viabilizar a coordenação entre os agentes. Além disso, destaca-se que a regulamentação ambiental vigente implica normas para transporte de resíduos sólidos. Os veículos devem ser licenciados e não é permitido transportar resíduos juntamente com produtos destinados ao consumo final. Dessa forma, a logística reversa para embalagens pós-consumo não pode acontecer pelo uso do mesmo veículo utilizado para entrega dos produtos no varejo, sendo necessária a contratação de transportadoras locais;

- Dificuldades de caráter estratégico: em procedimentos mais abrangentes, como no programa Carbono Neutro, o entrevistado destaca ainda uma dificuldade estratégica, pois "[...] há um forte risco associado às estratégias comerciais e de marketing (mix de vendas)", em decorrência dos elevados investimentos e da incerteza com relação à resposta do consumidor.

Fica claro um forte direcionamento dos procedimentos ao mercado, considerando que muitas ações ambientais podem ser valorizadas pelo consumidor, permitem alcance de melhor imagem da marca e referem-se, portanto, a incremento da competitividade. De fato, a empresa em análise tem buscado gerenciar seus impactos ambientais, prover inovações tecnológicas para gestão ambiental e controlar a emissão de GEEs.

As estratégias de inovação e de internacionalização, mencionadas na pesquisa de campo, estão também associadas a aspectos ambientais. Grande parte das inovações de produto e marketing está relacionada a melhorias ambientais (componentes menos poluentes, embalagens recicláveis e recicladas, produtos socioambientalmente responsáveis e uso de rótulos ambientais). A inserção no mercado externo, por sua vez, também depende de melhorias ambientais, à medida que deve-se atender a regulamentações específicas e buscar diferenciação de mercado via produtos com apelo ambiental. Isso é especialmente válido para o mercado europeu, no qual a inserção da empresa se dá com a linha de produtos com forte apelo ambiental.

Além disso, a gestão da rede de suprimentos também se mostra, para a empresa, como variável importante na condução de procedimentos ambientais, inclusive levando à formação de parcerias com fornecedores e coletores de resíduos, entre outros. Nesse caso, as dificuldades associadas a essas parcerias são apontadas e deveriam ser sanadas para permitir à empresa alavancar seu desempenho. A Figura 2 relaciona a empresa e o papel de alguns stakeholders (partes interessadas) no processo de gestão ambiental estratégica. Busca-se, pela figura, mostrar que a empresa depende da interação/participação de diversos stakeholders para realizar gestão ambiental estratégica, a fim de alcançar resultados almejados.

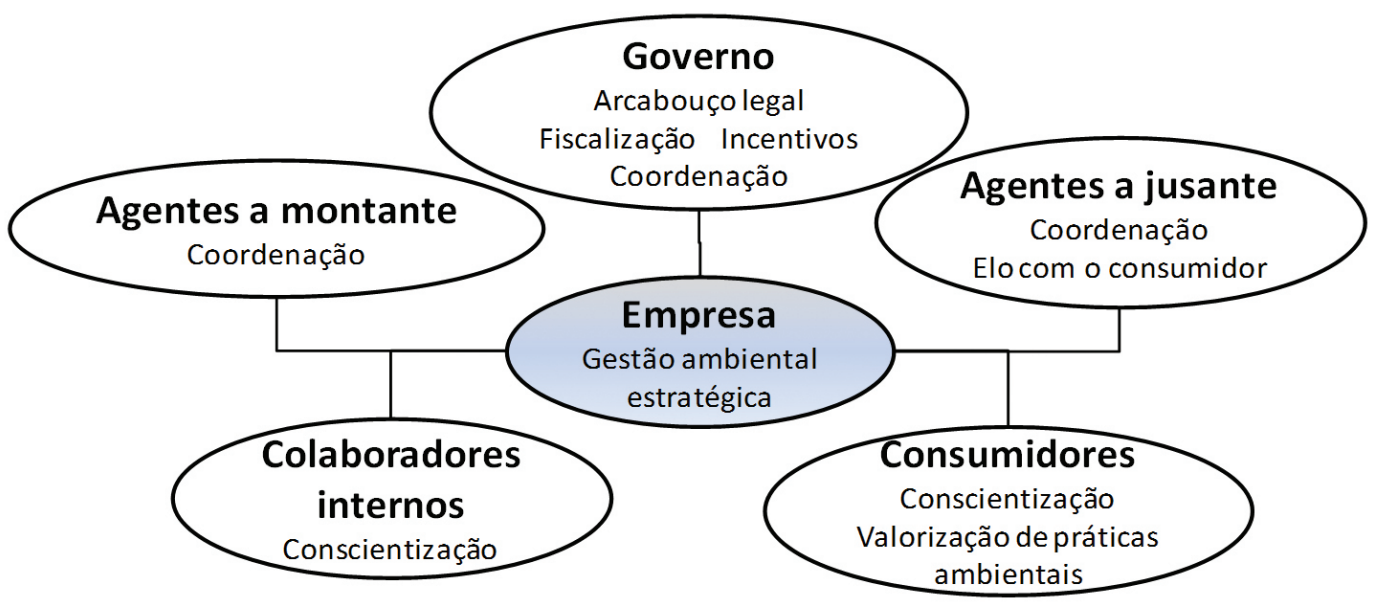

Figura 2. Gestão ambiental estratégica e interação com stakeholders. Fonte: elaborada pelos autores. 


\section{Considerações finais}

A necessidade de se adequar à nova dinâmica competitiva tem levado empresas dos mais diferentes setores a repensarem suas estratégias. Assim, aspectos ambientais têm sido relevantes e até mesmo destacados nas atividades empresarias.

Levando-se em conta os resultados do presente trabalho, percebe-se que as ações de caráter ambiental são condizentes com a estratégia empresarial à medida que: estão alinhadas à política ambiental da empresa; contam com o envolvimento da alta gerência; a missão, a visão e os valores da empresa remetem a aspectos ambientais; são definidas diretrizes e metas ambientais no planejamento estratégico. Além disso, nota-se que melhorias ambientais têm feito parte das atitudes empresariais ao longo dos anos, com a intensificação dos procedimentos na última década. Entende-se que a empresa posiciona-se estrategicamente em estágio avançado, dado que mostra-se proativa frente a problemas ambientais futuros e busca a excelência ambiental por meio de inovações de produto e processos e da amarração de questões ambientais à estratégia da organização.

No que concerne à competitividade e melhorias ambientais, ao se considerar o triple bottom line, entende-se que os procedimentos de cunho ambiental estão relacionados à busca de melhor desempenho pela empresa. $\mathrm{O}$ aspecto inovativo da gestão ambiental, conforme preconizado na teoria, é claramente observado na pesquisa de campo. As medidas ambientais destacadas incluem inovações de produto e processos, bem como a participação ativa da área de inovação de produtos.

Vale destacar ainda o papel do governo para incentivo e condução de melhorias ambientais. Observa-se, pelo estudo, que o poder público, por meio de regulamentações e políticas ambientais, vai além do exercício de pressões sobre as empresas. Mesmo para empresas que já assumem postura proativa frente a questões ambientais, o governo toma papel relevante, à medida que pode viabilizar a coordenação e a sistematização de ações ambientais dentre políticas ou programas específicos. Assim, mais do que criar leis e fiscalizar, o governo pode-se mostrar um importante agente de coordenação.

Por fim, enfatiza-se que o avanço da gestão ambiental estratégica na empresa depende da superação de dificuldades apontadas, tais como falhas de coordenação e dificuldades sociais e legais. Nesse sentido, também, políticas públicas, por meio de ecoinovações institucionais, poderiam ser direcionadas a gerar incentivos para maior comprometimento e coordenação entre os agentes.

\section{Referências}

ASSOCIAÇÃO BRASILEIRA DA INDÚSTRIA DE HIGIENE PESSOAL, PERFUMARIA E COSMÉTICOS - ABIHPEC. Panorama do setor. Higiene pessoal, perfumaria e cosméticos. ABIHPEC, 2010. Disponível em: <www.abihpec.org.br>. Acesso em: 10 dez. 2011.

ASSOCIAÇÃO BRASILEIRA DA INDÚSTRIA DE HIGIENE PESSOAL, PERFUMARIA E COSMÉTICOS - ABIHPEC. Panorama do setor: higiene pessoal, perfumaria e cosméticos. ABIHPEC, 2013. Disponível em: <www.abihpec.or.br>. Acesso em: 09 dez. 2013.

ASSOCIAÇÃO BRASILEIRA DA INDÚSTRIA DE HIGIENE PESSOAL, PERFUMARIA E COSMÉtICOS - ABIHPEC. Caderno de tendências: 2010/2011. São Paulo: 2011. Disponível em: <www.abihpec.org.br>. Acesso em: 05 fev 2011.

ALIGIERI, L.; ALIGIERI, L. A.; KRUGLIANKAS, I. Gestão socioambiental: Responsabilidade e sustentabilidade do negócio. São Paulo: Atlas, 2009.

ANDRADE, J. C. S. Desenvolvimento sustentado e competitividade: tipos de estratégias ambientais empresariais. In: TECBAHIA: Revista Baiana de Tecnologia, v. 12, n. 2, p. 71-86, maio/ago. 1997.

BARBIERI, J. C. Gestão ambiental empresarial: conceitos, modelos e instrumentos. 3. ed. São Paulo: Saraiva, 2011.

BROWN, D.; DILLARD, J.; MARSHALL, R. S. Triple

Bottom Line: a business metaphor for social construct. Barcelona: Departament d'Economia de 1'Empresa; Universitat Autònoma de Barcelona, 2006. (Document de Treball n. 06/2).

COMPANHIA DE TECNOLOGIA DE SANEAMENTO AMBIENTAL - CETESB; ASSOCIAÇÃO BRASILEIRA DA INDÚSTRIA DE HIGIENE PESSOAL, PERFUMARIA E COSMÉTICOS - ABIHPEC. Guia técnico ambiental da indústria de higiene pessoal, perfumaria e cosméticos. São Paulo: CETESB, 2006. Disponível em: <http://www.cetesb.sp.gov.br/tecnologia/ producao_limpa/documentos/higiene.pdf $>$. Acesso em: 20 dez. 2010.

ELKINGTON, J. Enter the triple bottom line. In: HENRIQUES, A.; RICHARDSON, J. (Eds.). The triple bottom line, does it all add up? Assessing the sustainability of business and CSR. London: Earthscan Publications Ltd, 2004. p. 01-16

FARRELL, G.; LUKESCH, R.; THIRION, S. Competitividade ambiental: conceber uma estratégia de desenvolvimento territorial à luz da experiência LEADER. Observatório Europeu LEADER. Bruxelas: FAO, jun. 2000. Disponível em: <http://www.fao.org/ sard/static/leader/pt/biblio/environment.pdf > . Acesso em: 20 fev. 2010.

FEDERAÇÃO DAS INDÚSTRIAS DO ESTADO DE SÃO PAULO - FIESP; CENTRO DAS INDÚSTRIAS DO ESTADO DE SÃO PAULO - CIESP. Agenda da conformidade ambiental da indústria paulista. FIESP/CIESP, 2006. Disponível em: <www.fiesp.com. br>. Acesso em: 10 nov. 2011.

FORSMAN, H. Environmental innovations as a source of competitive advantage or vice-versa? Business Strategy and Environment, v. 22, p. 306-320, 2013. http://dx.doi.org/10.1002/bse.1742

FUNDAÇÃO GETULIO VARGAS - FGV. Centro de Estudos em Sustentabilidade - GVCES. ISE Bovespa. 
GVCES/FGV, 2011. Disponível em <www.ces.fgvsp. br>. Acesso em: 12 jan. 2011.

GODOY, A. S. Pesquisa qualitativa: tipos fundamentais.

RAE - Revista de Administração de Empresas, v. 35, n. 3, maio/jun. 1995.

HOSKISSON, R. E. et al. Estratégia competitiva. São Paulo: Cengage Learning, 2009. PMid:19729089.

INSTITUTO AKATU; INSTITUTO ETHOS. O consumidor brasileiro e a sustentabilidade: atitudes e comportamentos frente ao consumo consciente, percepções e expectativas sobre a RSE. Pesquisa 2010. AKATU; ETHOS, 2010. Disponível em: <http://www. akatu.org.br>. Acesso em: 05 jan 2011.

IRALDO, F. et al. A literature review on the links between environmental regulation and competitiveness. Scoula Superiore Sant'Anna, 2009. Management \& Innovazione Working Paper 04/2009. Disponível em: $<$ http://onlinelibrary.wiley.com/doi/10.1002/eet.568/ pdf>. Acesso em: 10 fev. 2012.

JABBOUR, C. J. C. et al. Environmental management in Brazil: is it a completely competitive priority? Journal of Cleaner Production, v. 21, p. 11-22, 2012. http:// dx.doi.org/10.1016/j.jclepro.2011.09.003

MACEDO, F. et al. (Coords.) O valor do ISE. Principais estudos e a perspectiva dos investidores. São Paulo: BM\&F Bovespa; GVCES-FGV, 2012. Disponível em: $<$ http://www.bmfbovespa.com.br/Indices/download/OValor-do-ISE.pdf>. Acesso em: 10 jul. 2013.

MARTÍN-TAPIA, I.; ARAGÓN-CORREA, J. A.; RUEDAMANZANARES, A. Environmental strategy and exports in medium, small and micro-enterprises. Journal of World Business, v. 45, n. 3, p. 266-275, 2010. Disponível em: <http://www.sciencedirect.com/science/article/ pii/S1090951609000704>. Acesso em: 18 fev. 2012.

MOLLENKOPF, D. et al. Green, lean and global supply chains. International Journal of Physical Distribution \& Logistics Management. Vol. 40, n. 1/2, 2010.

NORTH, K. Environmental business management: an introduction. 2nd ed. Geneva: International Labour Office, 1997.

NOVAES, A. G. Logística e gerenciamento da cadeia de distribuição. Estratégia, operação e avaliação. 3. ed. Rio de Janeiro: Elsevier, 2007.

ORGANISATION FOR ECONOMIC CO-OPERATION AND DEVELOPMENT - OECD. Eco-Innovation in Industry. Enabling green growth. OECD, 2009.
Disponível em: <www.oecd.org>. Acesso em: 12 dez. 2010.

ORGANISATION FOR ECONOMIC CO-OPERATION AND DEVELOPMENT - OECD. Oslo Manual. Proposed guidelines for collecting and interpreting technological innovation data. 3rd ed. OECD, 2005. Disponível em: <www.oecd.org>. Acesso em: 20 jan. 2011.

ORSATO, R. J. Posicionamento ambiental estratégico. Identificando quando vale a pena investir no verde. Revista Eletrônica de Administraçao. REAd, v. 8, n. 6, nov./dez. 2002. Edição Especial 30.

PORTER, M. E. Estratégia competitiva: Técnicas para análise de indústrias e da concorrência. 5. ed. Rio de Janeiro: Campus, 1991.

PORTER, M.; VAN DER LINDE, C. Verde e competitivo: acabando com o impasse. In: PORTER, M. Competição: estratégias competitivas essenciais. Rio de Janeiro: Campus, 1999.

SANTIN, M. F. C. L. Os impactos da demanda por crédito de carbono sobre o mercado de certificações de reduções de emissões no Brasil, no âmbito do protocolo de Quioto. 2007. Dissertação (Mestrado)Pontifícia Universidade Católica do Rio Grande do Sul, Porto Alegre, 2007. PMCid:PMC2258728.

SCHULTZ, K.; WILLIAMSON, P. Gaining competitive advantage in a carbon-constrained world: strategies for European Business. European Management Journal, v. 23, n. 4, p. 363-391, 2005. http://dx.doi.org/10.1016/j. emj.2005.06.010

SOTO, J. A química sustentável: desafios, dilemas e perspectivas. In: ALMEIDA, F. (Org.). Desenvolvimento sustentável 2012-2050: Visão, rumos e contradições. Rio de Janeiro: Elsevier, 2012.

SOUZA, R. S. Evolução e condicionantes da gestão ambiental nas empresas. Revista Eletrônica de Administraçao. REAd, v. 8, n. 6, nov./dez. 2002. Edição Especial 30.

UNITED NATIONS ENVIRONMENT PROGRAMME - UNEP. Towards a Green Economy. Pathways to a sustainable development and poverty eradication. Nairobi: UNEP, 2011. Disponível em: <http:// unep.org/greeneconomy>. Acesso em: 23 abr. 2013.

WEBER, P. S. A Gestão Ambiental na Empresa. Revista Sanare, v. 12, 1999. Disponível em: <http://www. ambientebrasil.com.br>. Acesso em: 20 jun. 2007. 